\title{
A case report of palmoplantar psoriasis treated with homeopathic Secale cornutum
}

\begin{abstract}
Psoriasis is a common non-infectious disease, considered to be a chronic autoimmune condition, T-cell mediated, characterized by faster replacement of epidermis cells on the basal membrane level, consequently causing inflammation and scaling, affecting $2-3 \%$ of population. In palmoplantar psoriasis (PPP) fissures and bleeding aggravate patient's discomfort. Besides conventional dermatologic treatment, many patients choose homeopathic treatment for this condition due to their efficacy and lack of side-effects. In reports on homeopathic treatment of psoriasis the most used medicaments were so called polycrests, or big remedies (like Sulphur, Lycopodium, Natrum muriaticum, etc). In our article we report a case of PPP treated till recovery with a rare homeopathic remedy for this condition, Secale Cornutum, which was prescribed according to individualization of patient signs and symptoms.
\end{abstract}

Keywords: psoriasis, homeopathy, palmoplantar psoriasis, secale cornutum, acrocyanosis
Volume 13 Issue 2 - 2020

\section{Gheorghe Jurj}

Department of Clinical research, Asociatia Romana de Homeopatie Clinica, Romania

\section{Correspondence: Gheorghe Jurj, Department of Clinical research, Asociatia Romana de Homeopatie Clinica, Romania, Tel +40736038407, Email relujurj@gmail.com}

Received: July 3I, 2019 | Published: April 03, 2020
Abbreviations: PP, palmoplantar psoriasis; CAM, alternative medicine

\section{Introduction}

A non-infectious condition, related with T-cell immune disorders and genetically predisposition, as well as stress, psoriasis is relatively a common disease, with a prevalence of $2-3 \%$ of overall population. It is characterized by inflammation and rapid turn-over of epidermis cells leading to a variety of manifestations: redness, itching, thickening of skin, scales in plaques, fissures and bleeding. Palmoplantar psoriasis (PPP) accounts $3-4 \%$ of psoriasis cases and is a variety with lesions mainly on palms and soles, up to half presenting nails changes: deformations of nails, painful nails, separation of nails from the bed, color changes. PPP is often a very disturbing condition both because of physical symptoms (painful cracks, bleeding impeding the normal work) and psychologically (depression, self-image and self-esteem issues).

Conventional treatments like topical applications (of corticosteroids mailnly) systemic therapies, or immunomodifying biologicals sustained for long term, expose patients to side-effects, toxicity and possible long-term risk. Therefor patients look for different complementary and alternative medicine (CAM), among them homeopathy. Although meta-analyses of placebo controlled trials have shown inconsistent results, ${ }^{1}$ audits, ${ }^{2}$ observational,,${ }^{3,4}$ and cases reports ${ }^{5,6}$ published in different places of the world sustain the efficacy of homeopathic treatment in dermatological disorders.

One of the main principles for selecting an appropriate homeopathic remedy is individualization, depending of varying sign and symptoms of the patient, considered most characteristic, peculiar and specific for the individual. The most common remedies used to treat and improve psoriasis belong to the so-called polycrest category, or"big remedies" (Like Sulphur, Lachesis, Arsenicum album, Natrum Muriaticum, Sepia, etc $)^{7}$ even less commom remedies were used too (Hydorcotyle, Selenium, Kalium Arsenicosum, Kalium Bromatum, etc). In the present paper, we show a cure of PPP, using a rare remedy for this condition (we didn't find any other case in the literature or homeopathic repertories), Secale Cornutum, selected on some peculiar features of physical signs of the patient.

\section{Case report}

Male, white, 25 y.o. presenting psoriazis on hands for about 2 years, made more topical corticoids treatments on which he responded temporarily and then without effect.

On first consultation he presented some typical features of PPP as seen in photos 1-5, like erythematous base, hyperkeratosis, fissures and bleeding cracks, located on both hands, mostly on fingers and palms. The nails are distorted and corrugated. The most striking and peculiar aspect, which was the key sign for the selection of the remedy was acrocyanosis, with bluishness of fingers more accentuated through tips, with objective coldness but subjective aggravation to warmth (modalities of Secale Cornutum). As seen in photo 4 the base of lesions were bluish.

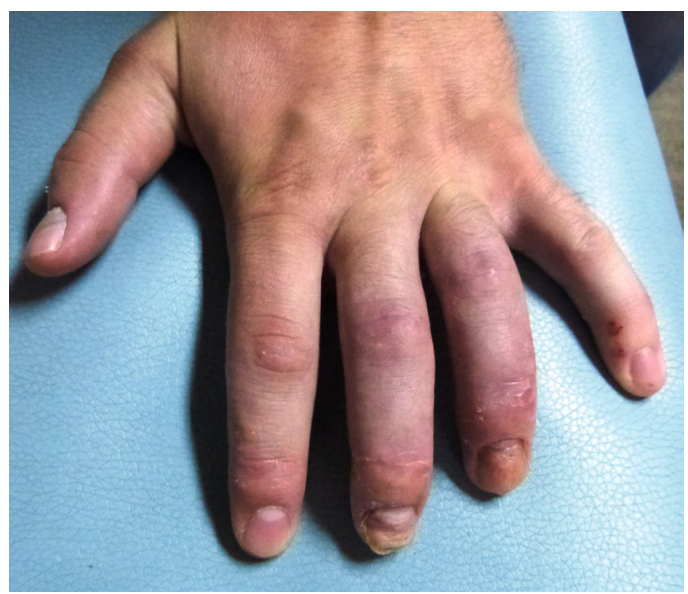

Figure I Left hand, Distorded nails, descuamation and acrocyanosis. 


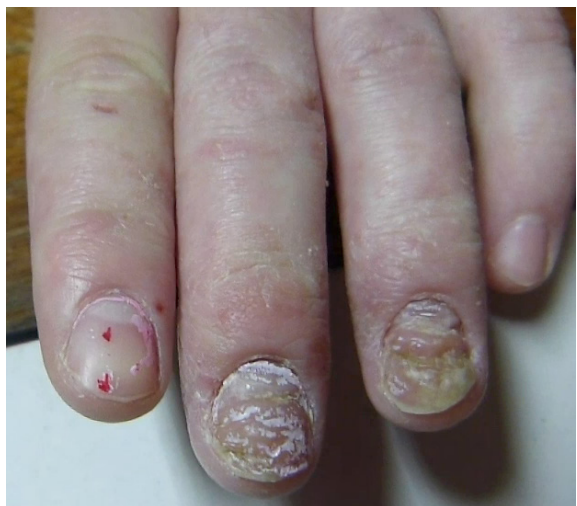

Figure IA Details nails.

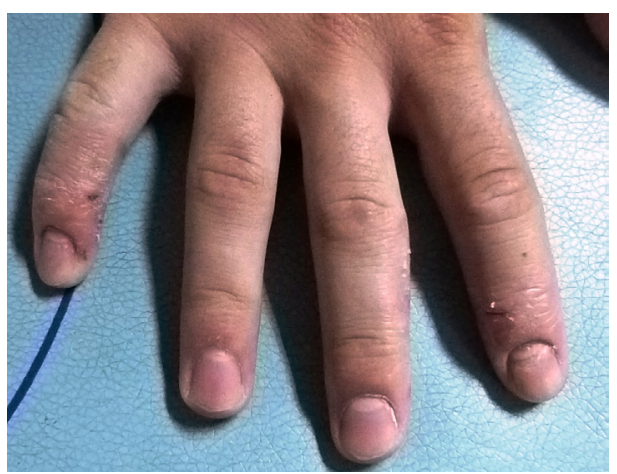

Figure 2 Right hand. Distorded nails, cracks and acrocyanosis.

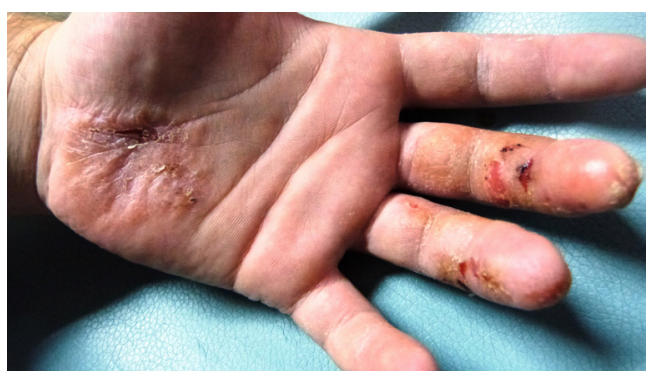

Figure 3 Left palm. Hyperkeratosis, bleeding fissures on palm and fingers.

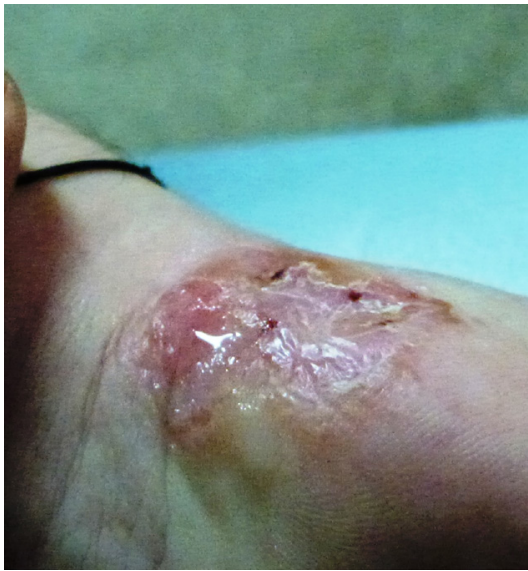

Figure 4 Detail of a lesion a right palm. Fissures, bleeding and exudation on a bluish, cyanotic base.

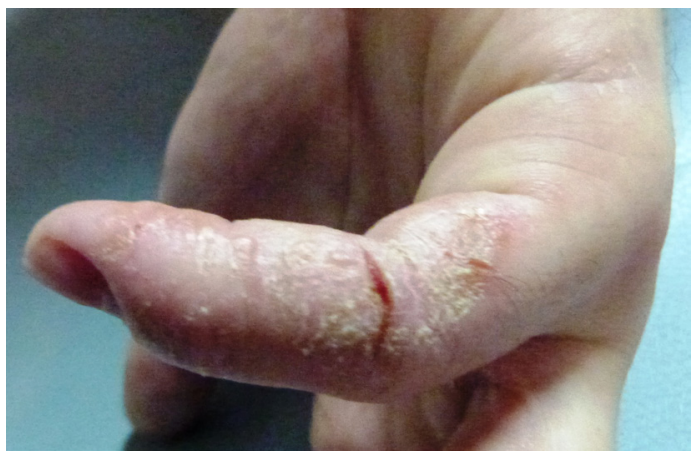

Figure 5 Detail right small fingers. Hyperkeratosis, bleeding deep fissure, bluish tip Secale cornutum was prescribed in low dilutions, X6 for two weeks, followed by XIO for another 2 weeks and then he repeated this alternance till the next consultation on 2 months. The reason for prescribing low dilution was the strict physical similarity, based on accrocyanosis, without notable mental symptoms. In Photos 6 to 8 the 2 months follow up.

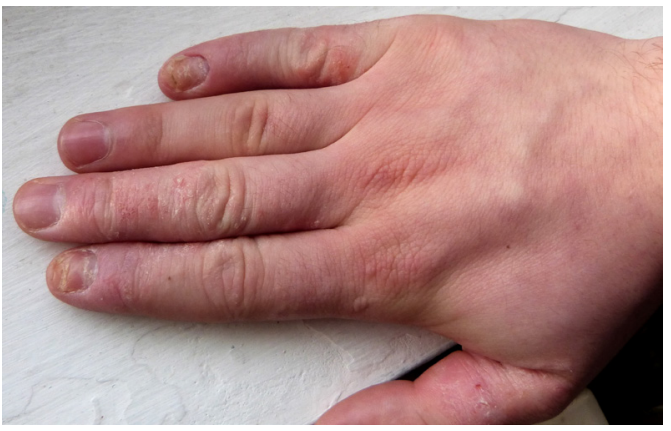

Figure 6 Right hand follow up 2 months. Improvement of lesions and fissures.

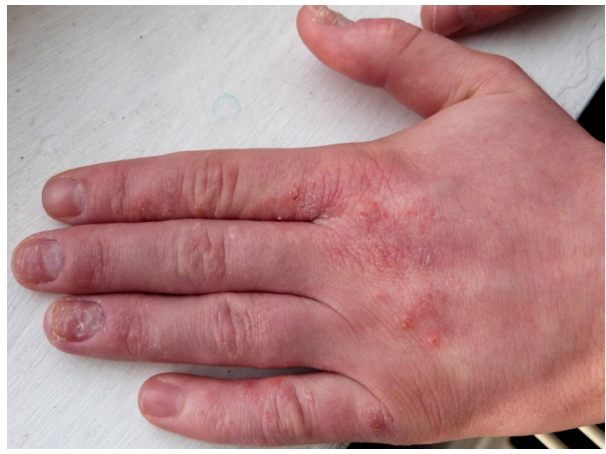

Figure 7 Left hand follow up 2 months. General improvement, cyanosis improved but still visible.

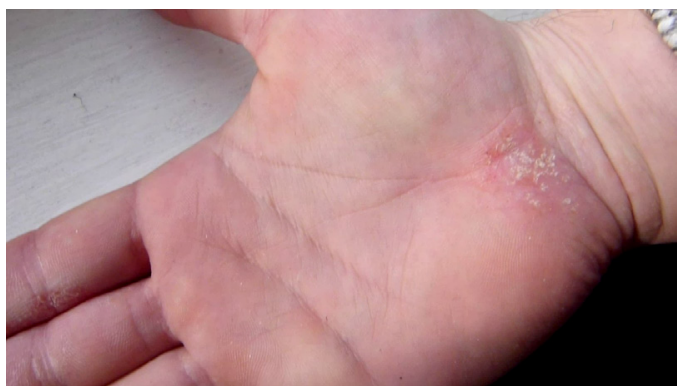

Figure 8 Right hand, follow up 2 months, improvement of palmar lesion but still a degree of acrocyanosis. The next follow up was at 6 months, keeping the same treatment, Secale Cornutum $\times 6$ and $\times 10$ in alternances at 2 weeks. 


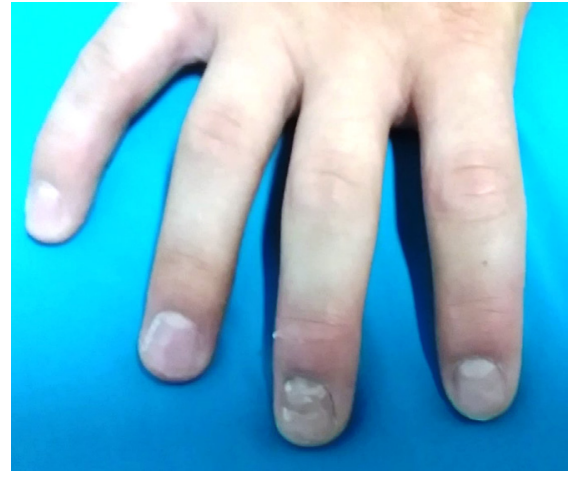

Figure 9 Right hand at 6 months. Complete recover of psoriasis lesions, nails improvement.

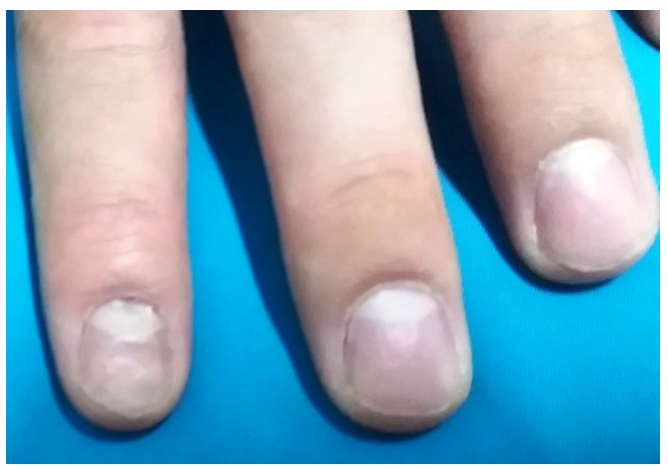

Figure 10 Left hand, Improvement of nails and cyanosis.

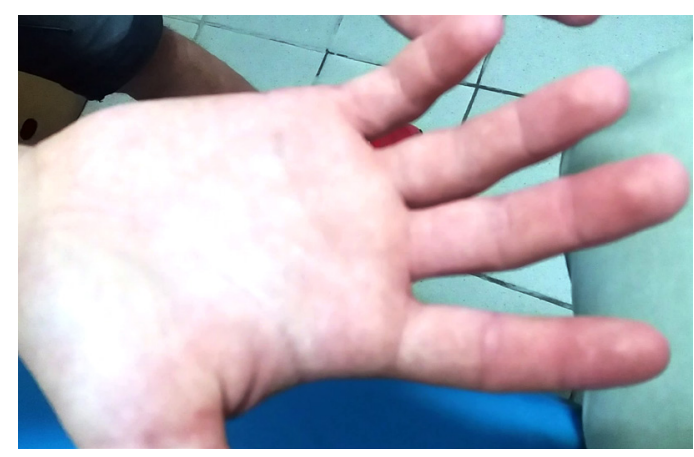

Figure II Right hand at 6 months. Recover of psoriasis, much better with subjective and objective signs of acrocyanosis.

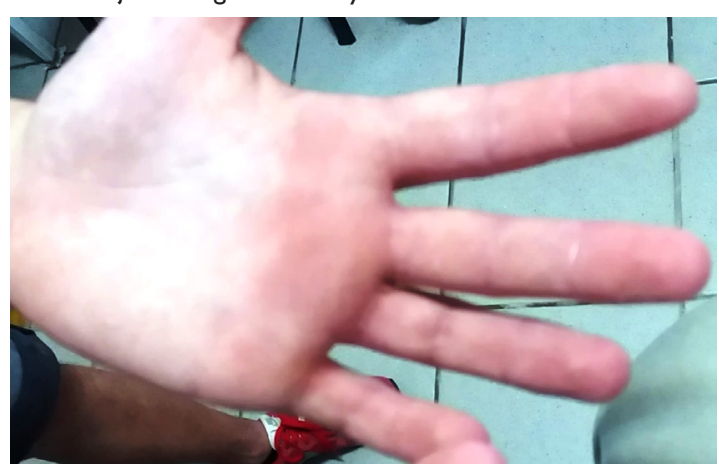

Figure 12 Left hand at 6 months follow up. Psoriasis lesions practically remitted and acrocyanosis improved substantially. The next follow up was at I year after. He continued the treatment for 8 months till complete recover.

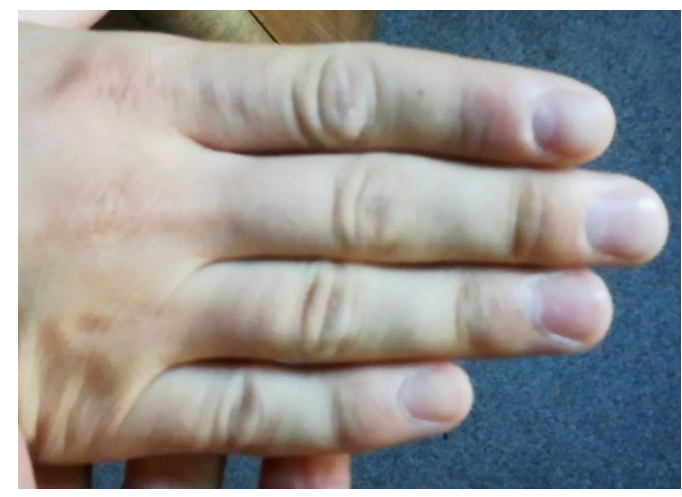

Figure I3 Right hand. Complete recover of psoriasis lesion, nails and acrocyanosis.

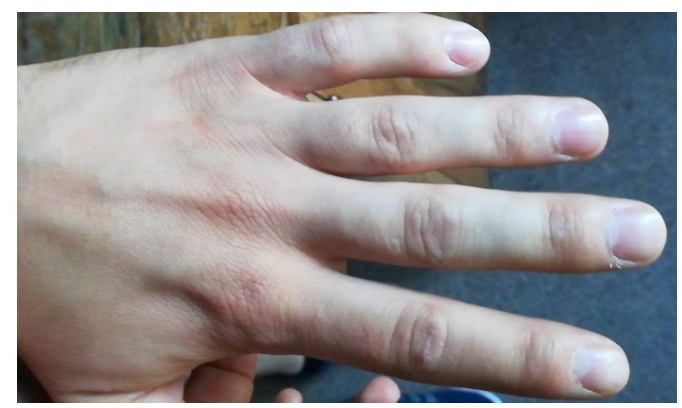

Figure I 4 Left hand. Complete recover of all signs.

\section{Discussion}

The present case, even if it can be considered as an anecdotal evidence, is interesting for at least 3 reason: 1) it shows efficacy of homeopathy in a case resistant to conventional dermatological topic applications; 2) It show the efficacy of a rarely used homeopathic remedy in this condition; 3 ) it show the necessity of individualization in the homeopathic prescription, according to most peculiar signs and symptoms of the actual patient.

\section{Conclusion}

Even it is a case study, in the opinion of the author, it provides insight about 3 aspects: a) the efficiency of homeopathic treatment in palmoplantar psoriazis; b) for a valuable homeopathic treatment an individualization of cases are necessary, taken into consideration both general and local signs and symptoms; c) Secale Cornutum as a homeopathic remedy was seldom use for the treatment of this condition, although the case shows trustful criteria for further prescription. Larger studies on the item, with this remedy or others, are however requested to formulate more detailed conclusions.

\section{Acknowledgments}

None.

\section{Conflicts of interest}

Author declares that there are no conflicts of interest.

\section{Funding}

None. 


\section{References}

1. Simonart T, Kabagabo C, De Maertelaer V. Homoeopathic remedies in dermatology: a systematic review of controlled clinical trials. BJD. 2011;165 (4);875-905.

2. Sevar R. Audit of outcome in 455 consecutive patients treated with homeopathic medicines. Homeopathy. 2005;94(4):215-221.

3. Waisse-Priven S, Jurj G, Thomaz LCL, et al. Individualized homeopathic treatment of dermatological complaints in a public outpatient clinic. Homeopathy. 2009;98(3):149-153.

4. Witt CM, Lutdke R, Willich SN. Homeopathic treatment of patients with psoriasis - a prospective observational study with 2 years follow-up. $J$ Eur Acad Dermatol Venereol. 2009;32(5):538-543.

5. Nwabudike LC. Palmar and plantar psoriasis and homeopathy - Case reports. Our Dermatol Online. 2017;8(1):66-69.

6. Rajendran ES. Psoriasis and Natrum Muriaticum Alg. Homoeo Zeitung. $2005 ; 250-283$.

7. Sharma MP. Psoriasis cure with Homeopathy. JDDT. 2017;1(5). 